\title{
Kumulert sum ved overvåking av postoperative sårinfeksjoner
}

\begin{abstract}
Postoperative sårinfeksjoner følges gjennom Norsk overvåkingssystem for antibiotikabruk og helsetjenesteassosierte infeksjoner. Om slike data skal være nyttige, bør de tidlig kunne påvise trender og være enkle å forstå. Folkehelseinstituttets verktøy for å fremstille slike data tilfredsstiller ikke disse kravene. Vi oppfordrer til bruk av kumulert sum, som har klare fordeler sammenliknet med dagens verktøy.
\end{abstract}

Alvorlige postoperative sårinfeksjoner er sjeldne hendelser, og for at ledelsen ved sykehusene skal kunne ta riktige beslutninger om forbedringsarbeid og pasientsikkerhet, må dataene fra Norsk overvåkingssystem for antibiotikabruk og helsetjenesteassosierte infeksjoner (NOIS) gjøres lett forståelige. De bør også vise utviklingen over tid, slik at man tidlig kan påvise trender. Inngrepene som inngår i overvåkingssystemet er koronarkirurgi, hofteprotesekirurgi, keisersnitt, galleblære- og colonreseksjon (1). Folkehelseinstituttet analyserer dataene de mottar og avgir årsrapporter til sykehusene. Gjennom folkehelseinstituttet tilbys smittevernansatte også tilgang til NOISnett - en tilgangsbegrenset portal som muliggjør uttrekk av rapporter for eget sykehus (2). Vi mener imidlertid at rapportene som tilbys av Folkehelseinstituttet er for vanskelige å tolke og derfor gir for lite beslutningsstøtte til ledelsen.

Eksempler på rapporter fra Folkehelseinstituttet er vist i figur 1-3. Årsrapporten fra Folkehelseinstituttet sendes på e-post til smittevernpersonell ved sykehusene hver sommer og viser siste innsamlingsperiode versus samlet historisk gjennomsnitt (fig 1). Fremstillingen er enkel å forstå, men den er grov og maskerer prosessens tidsutvikling. Eksempler på tilbud gitt gjennom NOISnett er vist i figur 2 og 3 . Resultatrapporten (fig 2) viser insidens av infeksjoner ved eget sykehus sammenliknet med tilsvarende data fra andre sykehus. Her ser man ikke tidsutviklingen. Figur 3 er et g-diagram. Her plottes antall ukompliserte inngrep mellom hvert tilfelle av infeksjon. Denne metoden er godt egnet til fremstilling av hendelser som skjer sjelden $(3,4)$, og har vist seg å være et nyttig verktøy i smittevernarbeid $(5,6)$. G-diagram er bedre egnet til å følge prosesser enn grafikken vist i figur 1 og 2 . En ulempe er at tidsaksen blir fortegnet fordi man i den kun plotter infeksjoner og ikke inngrep fortløpende. Når man ikke kan følge en sann tidsakse, blir diagrammet utfordrende å tolke for det utrenede øye. I tillegg til de viste eksemplene tilbyr NOISnett en kvalitetsrapport som gir detaljerte, tabellariske resultater for en valgt periode, men ikke tidsutviklingen.
Legediagnostiserte infeksjoner (\%)

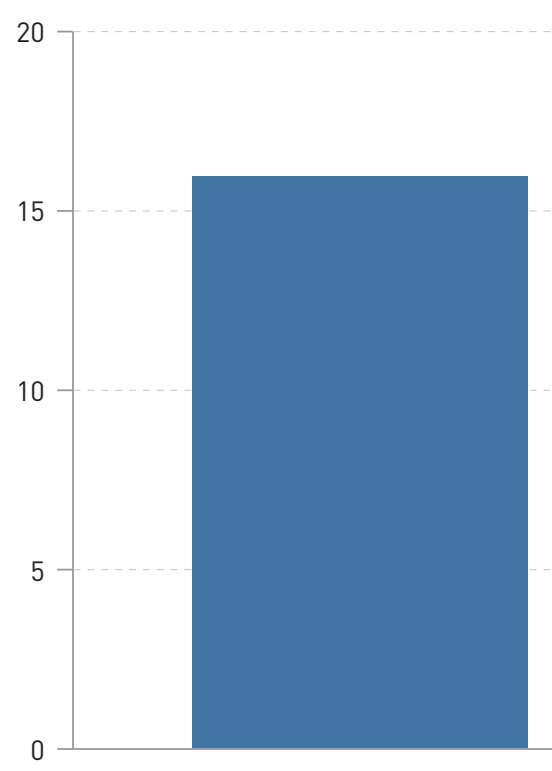

2011-13

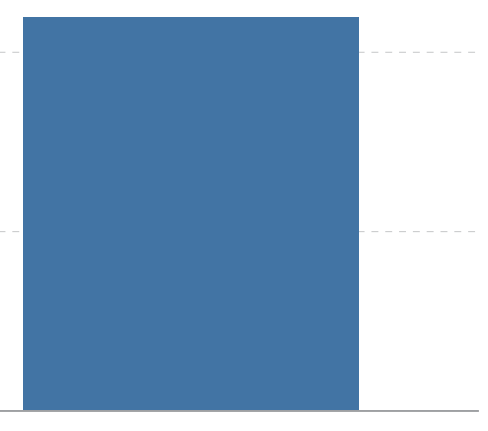

2014
Figur 1 Eksempel på en årsrapport for Norsk overvåkingssystem for antibiotikabruk og helsetjenesteassosierte infeksjoner (NOIS) fra Folkehelseinstituttet. Data for colonreseksjoner ved Bærum sykehus 2011-14

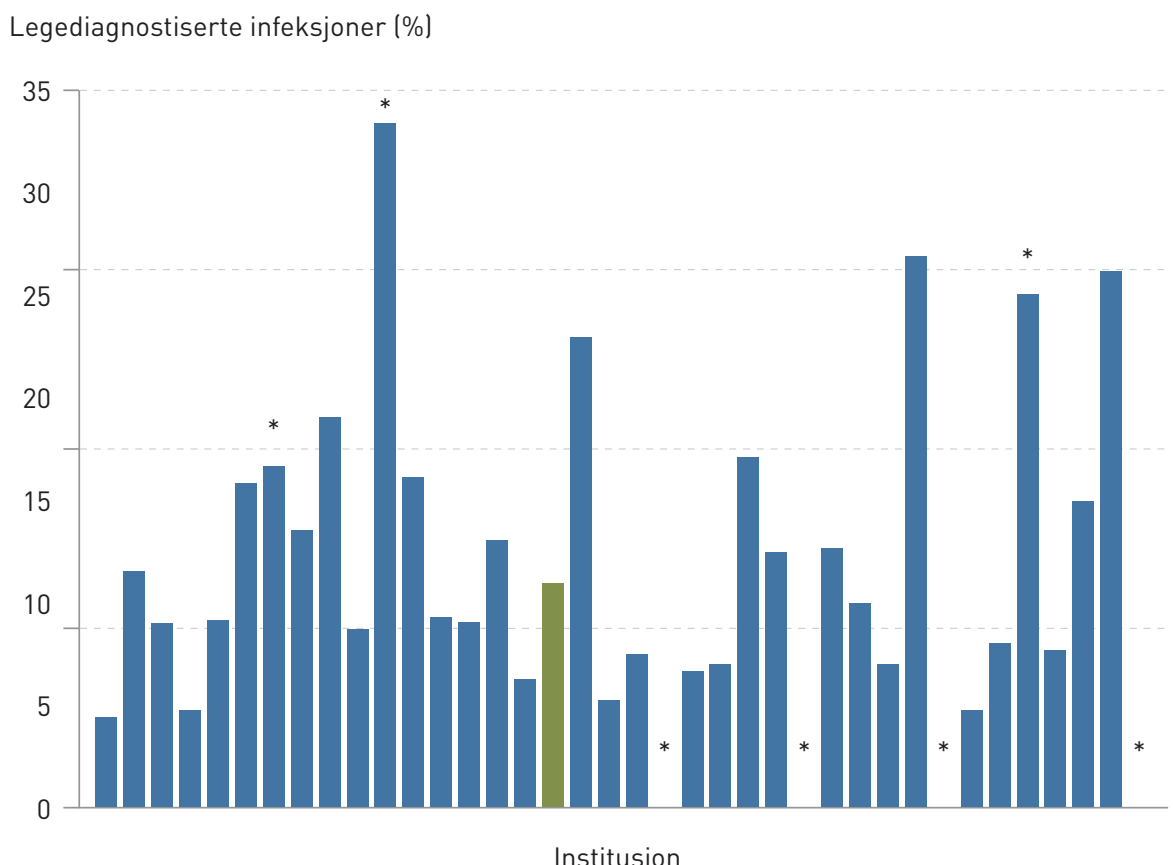

Figur 2 Eksempel på en resultatrapport fra NOISnett (2). Data for colonreseksjoner ved Bærum sykehus. Grønn stolpe = egen institusjon (vises ikke dersom det ikke var infeksjoner). Blå stolpe = annen institusjon. Åpen plass = institusjon som har overvåket inngrepet, men ikke har infeksjoner. Stjerne = institusjon som har gjennomført færre enn 21 inngrep 
Antall inngrep mellom alvorlige infeksjoner

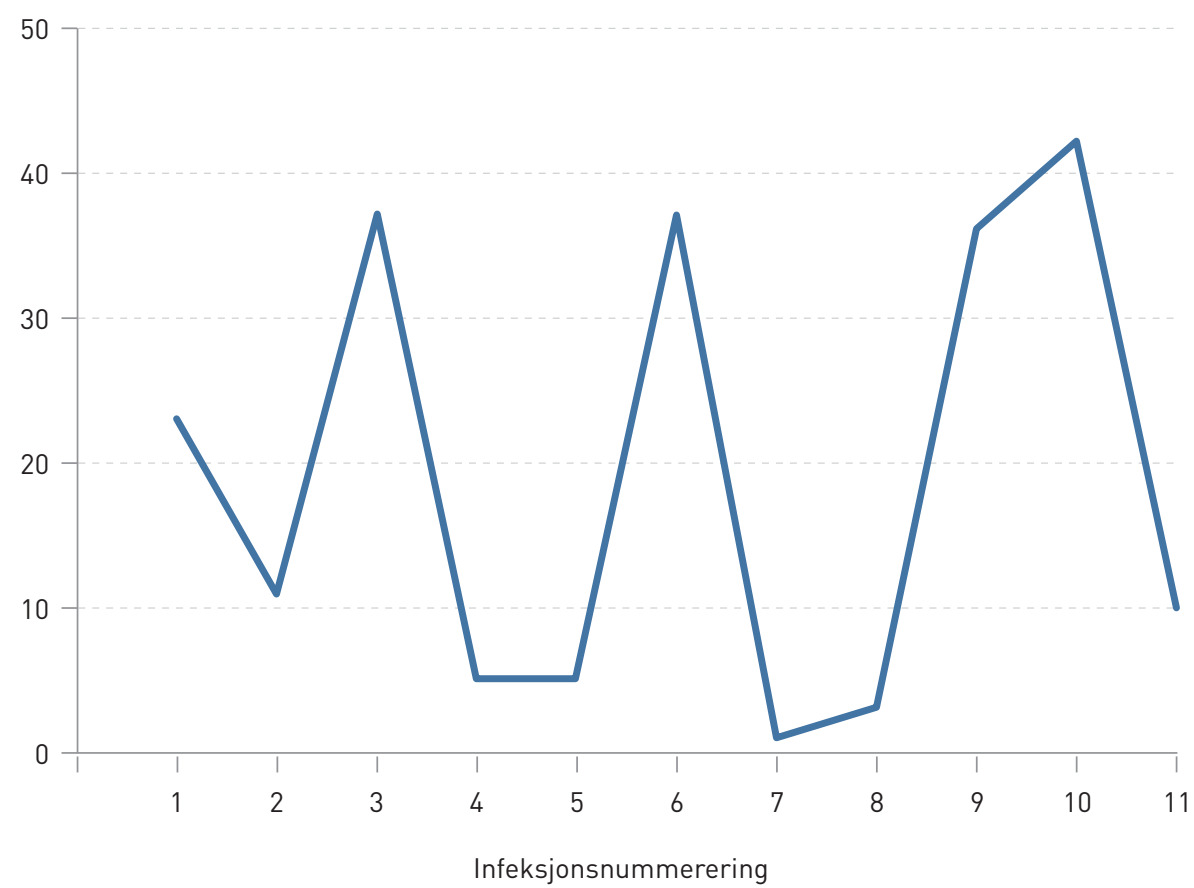

Figur 3 Eksempel på et g-diagram fra NOISnett (2). Data for colonreseksjoner ved Bærum sykehus

Alvorlige infeksjoner (\%)

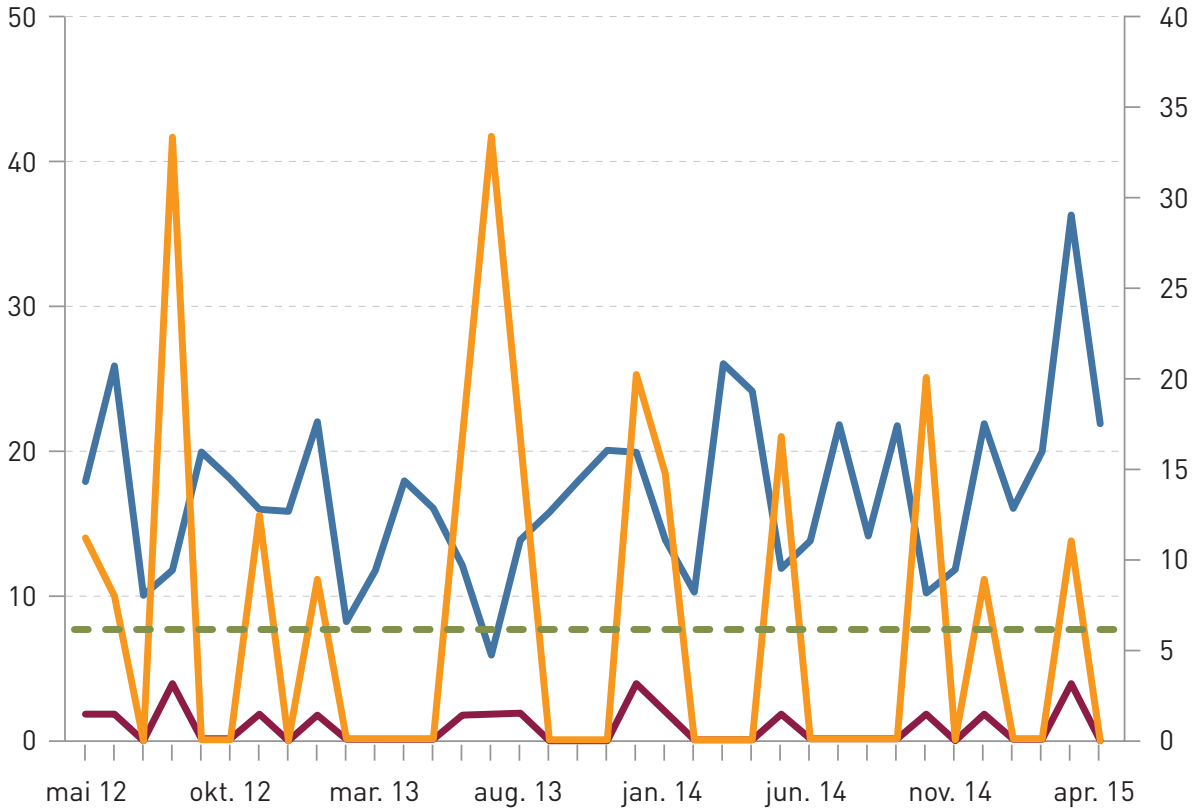

Antall inngrep

Antall alvorlige infeksjoner

Insidens (alvorlige infeksjoner)

Nasjonal insidens 2014

Figur 4 Eksempel på data fremstilt som periodisk (månedlig) insidens (gul kurve, høyre y-akse). NOIS-data for colonreseksjoner ved Bærum sykehus mai 2012-april 2015

\section{Erfaring fra Vestre Viken}

Vi mener det er viktig å kunne følge tidsutviklingen i dataene fra Norsk overvåkingssystem for antibiotikabruk og helsetjenesteassosierte infeksjoner, og vår erfaring er at smittevernmiljøene på norske sykehus ofte velger hjemmelagde systemer for å få til dette. Mange, inkludert Vestre Viken, bruker periodisk insidens (fig 4). Ulempen med denne metoden er at den fyller figurer med statistisk støy som vanskeliggjør påvisning av trender.

For å kunne gjøre overvåkingsdataene enklere å forstå har vi tatt kumulert sum (CUSUM) inn i vår portefølje for NOISdata. Dette verktøyet er robust og enkelt og kan raskt avsløre endringer i insidens (7-9). Kumulert sum reduserer statistisk støy sammenliknet med periodisk insidens, og dermed glattes kurver. Dette muliggjør tidlig påvisning av trender. Et eksempel er vist $i$ figur 5. Tidsutviklingen $\mathrm{i}$ insidensen er lett å lese ut av figuren. I Vestre Viken har vi valgt kumuleringsintervall på 24 måneder, men et annet intervall kan gjerne velges.

Bruk av kumulert sum gjør dataene lette å forstå og kan tidlig avsløre trender. Dermed kan ledelsen få avgjørende beslutningsstøtte. Vi mener at kumulert sum er et nyttig supplement til Folkehelseinstituttets nåværende tilbud for data fra Norsk overvåkingssystem for antibiotikabruk og helsetjenesteassosierte infeksjoner, og vi oppfordrer Folkehelseinstituttet til å ta verktøyet inn i sin portefølje.

\section{Ellen Brustad}

Mette Walberg

mette.walberg@vestreviken.no

Mette Walberg (f. 1958) er spesialist i medisinsk mikrobiologi, smittevernoverlege i Vestre Viken og leder av styret for Norsk forum for smittevern i helsetjenesten.

Forfatter har fylt ut ICMJE-skjemaet og oppgir ingen interessekonflikter.

Ellen Brustad (f. 1959) er bioingeniør og spesialrådgiver i smittevernavdelingen i Vestre Viken, med spesialansvar for overvåking innenfor smittevern.

Forfatter har fylt ut ICMJE-skjemaet og oppgir ingen interessekonflikter.

\section{Litteratur}

1. FOR-2005-06-17-611. Forskrift om Norsk overvåkingssystem for antibiotikabruk og helsetjenesteassosierte infeksjoner (NOIS-registerforskriften). https://lovdata.no/dokument/SF/ forskrift/2005-06-17-611 (8.10.2015)

2. NOISnett. www.fhi.no/helseregistre/ nois-prevalens-undersokelser (8.10.2015).

3. Benneyan JC. Number-between g-type statistical quality control charts for monitoring adverse events. Health Care Manage Sci 2001; 4: 305-18. 
Alvorlige infeksjoner [\%]

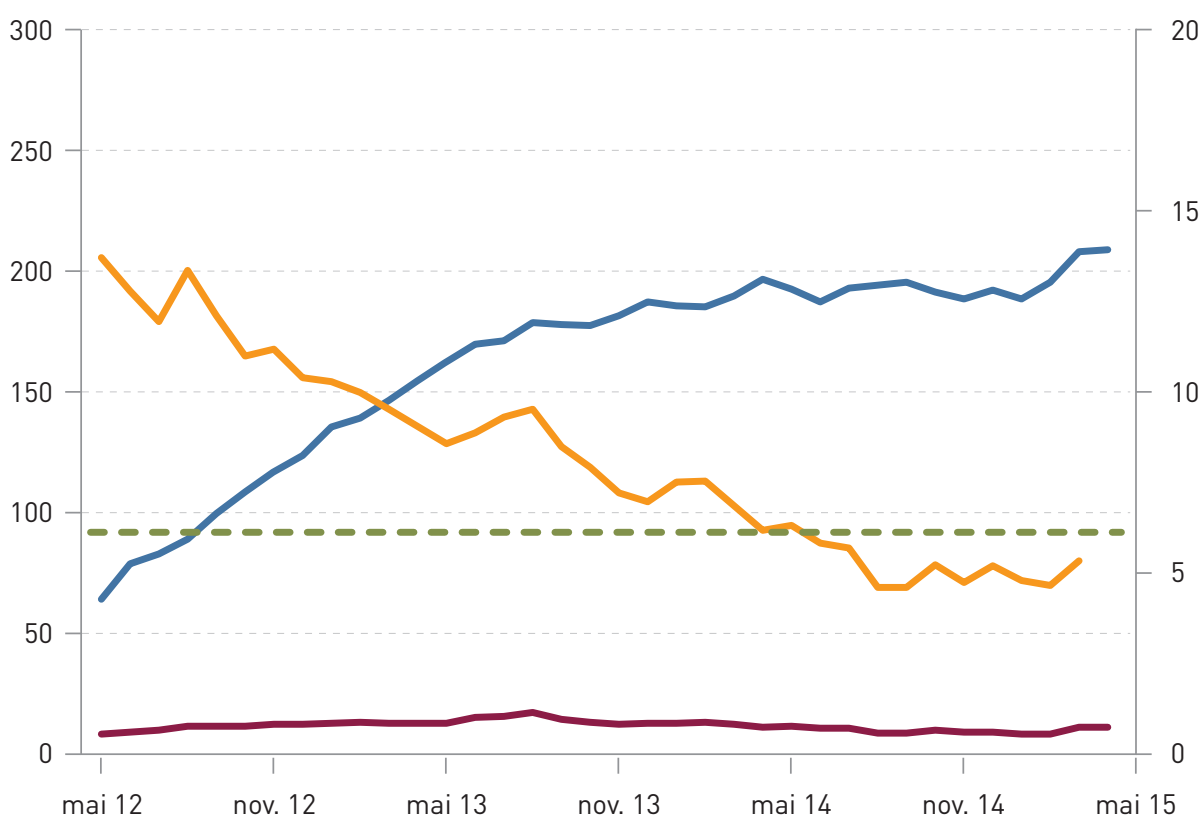

4. Benneyan JC. Performance of number-between g-type statistical control charts for monitoring adverse events. Health Care Manage Sci 2001; 4: $319-36$.

5. Walberg M. Frøslie KF, Røislien J. Local hospital perspective on a nationwide outbreak of Pseudomonas aeruginosa infection in Norway. Infect Control Hosp Epidemiol 2008; 29: 635-41.

6. Dyrkorn OA, Kristoffersen M, Walberg M. Reducing post-caesarean surgical wound infection rate: an improvement project in a Norwegian maternity clinic. BMJ Qual Saf 2012; 21: 206-10.

7. Williams SM, Parry BR, Schlup MM. Quality control: an application of the cusum. BMJ 1992; 304 : 1359-61.

8. Parikh AM, Park AM, Sumfest J. Cumulative summation (CUSUM) charts in the monitoring of hypospadias outcomes: a tool for quality improvement initiative. J Pediatr Urol 2014: 10: 306-11.

9. Wohl $\mathrm{H}$. The cusum plot: its utility in the analysis of clinical data. N Engl J Med 1977; 296: 1044-5.

Mottatt 25.8. 2015, første revisjon innsendt 24.8. 2015, godkjent 8.10 2015. Redaktør: Lise Mørkved Helsingen.

Publisert først på nett.

Antall inngrep (KUM 24 måneder)

Antall alvorlige infeksjoner (KUM 24 måneder)

Insidens alvorlige infeksjoner (KUM 24 måneder)

Nasjonal insidens 2014

Figur 5 Eksempel på bruk av kumulert sum (CUSUM) ved Smittevernavdelingen, Vestre Viken. NOIS-data for colonreseksjoner ved Bærum sykehus mai 2012-mai 2015. Tidsutviklingen i insidensen ses som gul kurve. Antall inngrep (nevneren) vises som blå kurve, antall alvorlige postoperative sårinfeksjoner (telleren) vises som rød kurve. Teller og nevner avleses på venstre $y$-akse, mens insidensen avleses på høyre $y$-akse. Stiplet kurve viser nasjonalt gjennomsnitt for 2014 